\title{
Capítulo IX Nexos sutiles entre souvenirs y turismo
}

\section{Chapter IX Subtle links between souvenirs and tourism}

ROJAS-COPA, Aline Estrella†*

Universidad Autónoma de Guerrero

ID 1 ${ }^{\mathrm{er}}$ Autor: Aline Estrella, Rojas-Copa / CVU CONACYT ID: 777001

DOI: $10.35429 / \mathrm{H} .2019 .1 .133 .146$

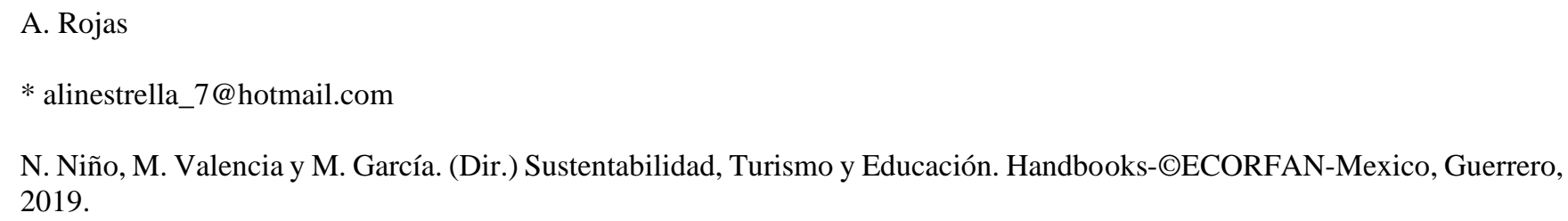




\title{
Resumen
}

Las artesanías juegan un papel fundamental en la identidad cultural de los pueblos toda vez que permiten transmitir un legado hacia las nuevas generaciones por medio de piezas únicas de calidad. El objetivo central fue sintetizar las relaciones existentes entre souvenirs y turismo en el destino de playa de Acapulco, Guerrero, México. La metodología consistió en trabajo documental donde se siguió el enfoque geográfico al interrelacionar los factores económicos, sociales y ambientales, enriquecido con un método mixto donde se aplicaron técnicas cualitativas como la observación participante y aplicación de 673 cuestionarios con diez preguntas cerradas de si o no. Entre los resultados se tuvieron que a) 638 turistas ostentan como primera opción de compra adquirir un souvenir o recuerdo de su estancia y $b$ ) existen nexos sutiles entre la adquisición de souvenirs y la práctica turística debido a la recesión económica mexicana. Las conclusiones fueron 1) los turistas nacionales y extranjeros que visitan Acapulco tienen en su imaginario adquirir uno o más souvenirs como recuerdo y para compartir su experiencia con la familia y 2) la importancia del apoyo financiero por parte de la secretaría de turismo municipal hacia la actividad artesanal en todas sus manifestaciones.

\section{Acapulco, Artesanías, Mercados de artesanías, Souvenirs, Turismo}

\begin{abstract}
The handicrafts play a fundamental role in the cultural identity of the people since they allow to transmit a legacy to the new generations through unique pieces of quality. The main objective was to synthesize the relationships between souvenirs and tourism in the destination of Acapulco beach, Guerrero, Mexico. The methodology consisted of documentary work where the geographical approach was followed by interrelated economic, social and environmental factors, enriched with a mixed method where qualitative techniques were applied such as participant observation and application of 673 questionnaires with ten closed questions of yes or no. Among the results were that a) 638 tourists have as a first purchase option to acquire a souvenir or souvenir of their stay and b) there are subtle links between the acquisition of souvenirs and tourist practice due to the Mexican economic recession. The conclusions were 1) national and foreign tourists visiting Acapulco have in their imagination to acquire one or more souvenirs as a souvenir and to share their experience with the family and 2) the importance of financial support from the municipal tourism secretariat towards Craft activity in all its manifestations
\end{abstract}

\section{Acapulco, Handicrafts, Crafts markets, Souvenirs, Tourism}

\section{Introducción}

La dupla de capitales culturales y naturales, ha triunfado en diversos países que buscan aumentar sus percepciones económicas a través de artículos que destaquen singularidades naturales de su medio. La República Mexicana cuenta con una amplia riqueza cultural, esto se refleja en la diversidad de artesanías que caracterizan a cada estado, esta actividad y su correlación con el medio se remonta a los orígenes del ser humano. La ciudad de Acapulco en Guerrero, México; es un sitio especial en gran parte por sus características ambientales entre ellas cabe destacar al clima tropical con lluvias en verano (Aw); temperatura media anual de $26.5^{\circ} \mathrm{C}$; precipitaciones torrenciales entre los meses de mayo a noviembre además de una topografía irregular. La otra parte, la integra el factor humano donde los prestadores de servicios turísticos atienden de manera entusiasta a los visitantes nacionales y extranjeros (Niño \& Bergeret, 2014).

En la actualidad, el medio ambiente ejerce un rol fundamental en los ámbitos nacional y mundial, debido a que el uso racional de los recursos es esencial para el desarrollo de diversas actividades económicas un ejemplo de ello, es la actividad artesanal que en la actualidad recibe escasa atención por parte de algunas autoridades del ramo, lo cual se aprecia a través de la carencia de saberes entre los consumidores y tomadores de decisiones e inclusive entre los propios actores locales acerca de las ventajas de ésta en los diversos ámbitos económico, social, ambiental y productivo. Las artesanías son un recurso relevante para el sector turístico que busca revalorar las tradiciones populares, por tanto, las representaciones elaboradas en la ciudad de Acapulco, se consideran como fruto de la cultura y naturaleza, debido a la variedad de figuras como: chimpancés, delfines, garzas, armadillos, serpientes y pericos (Ver figura 9.1). 
Figura 9.1 Artesanías de Chimpancés

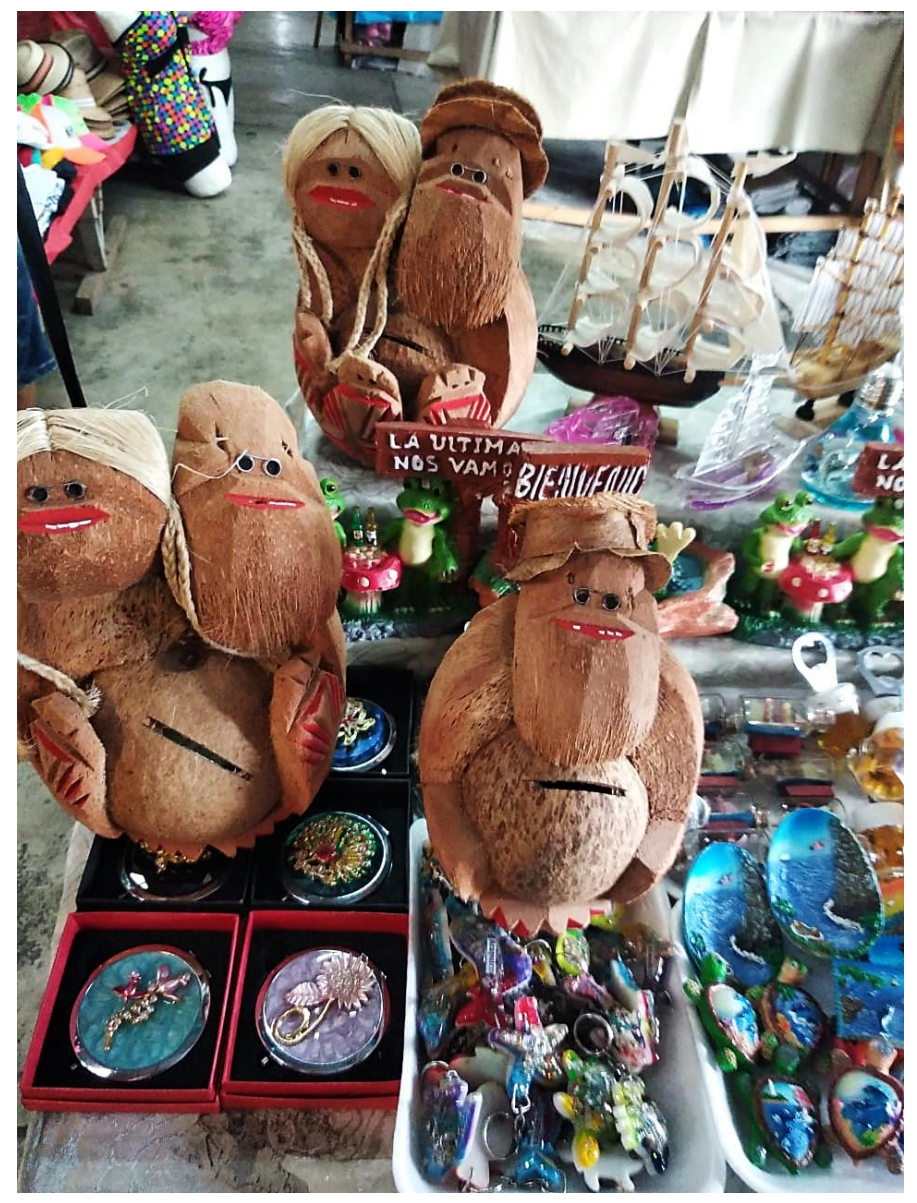

Fuente: Rojas, 2019

Acorde a datos proporcionados por el Consejo Nacional de Cocoteros (CONACOCO, 2017), destacan a esta materia prima como una fuente importante en los ramos económicos y laborales, en particular en los estados de: Guerrero, Oaxaca, Colima y Tabasco. En el presente, la palma de coco se encuentra sobreutilizada debido a la cantidad de artículos que se pueden conseguir de ella (Yasmin, 2009). Un aprovechamiento integral, se sustenta en obtener los mejores resultados en los ámbitos ecológicos y financieros, en el caso específico del cocotero, se pueden elaborar muebles, artesanías, dulces, aceites, agua, entre otros, asimismo su reutilización impacta de forma positiva en el medio ambiente local. Por lo cual es necesario, este tipo de estudio integrador que analice las características socioeconómicas de los negocios relacionados con la venta de souvenirs, además de aportar información actual en relación a la venta de estos productos a infinidad de visitantes. Es por esto, que el objetivo general del ensayo es sintetizar las relaciones existentes entre souvenirs y turismo. En México, la Ley General de Equilibrio Ecológico y la Protección al Ambiente (LGEEPA) conceptualiza al desarrollo sustentable como "el proceso evaluable mediante criterios e indicadores de carácter ambiental, económico así como el social, que tienden a mejorar la capacidad de vida junto con la productividad de las personas, fundadas en medidas propias de preservación del equilibrio ecológico y protección al ambiente, así como aprovechamiento de los recursos naturales, de manera que no se comprometa la satisfacción de las necesidades de las generaciones futuras, establece que el aprovechamiento sustentable es la utilización de los recursos en forma que se respete la integridad funcional así como también las capacidades de carga de los ecosistemas que forman parte dichos recursos por periodos indefinidos" (Burguete, 2007).

\subsection{Metodología}

En primer lugar, se recurrió a la lectura, selección y análisis de libros, guías impresas que indican los atractivos del puerto de Acapulco, revistas y publicaciones que anuncian los paquetes y ofertas para los turistas, además de folletos de información que detallan las bellezas naturales y artificiales como atractivos locales (Lesur, 2006). También, se recurrió a información digital e impresa existente sobre: palmeras, coco, artesanías con base en el coco, medio ambiente (Niño, 2014), turismo (Niño \& Bergeret, 2012) y sustentabilidad (Ruiz \& Niño, 2014). Dicho trabajo fue complementado con observación participante y aplicación de un cuestionario. 
El método de trabajo se sustentó en el enfoque geográfico al interrelacionar los factores físicos, bióticos, económicos, sociales y ambientales. Lo cual, permitió el análisis del fenómeno simbólico del souvenir. Ello, contribuyó a una mejor comprensión de los "recuerdos" que adquiere el turista cuando visita el puerto de Acapulco.

Para ello, el alcance investigativo fue analítico con diseño metodológico mixto. El diseño mixto empleado comprendió dos etapas: la primera, correspondió a la lectura, selección y análisis de información digital e impresa existente sobre: palmeras, coco, artesanías con base en el coco, medio ambiente (Ibídem, 2014), turismo (Ibídem, 2012) y sustentabilidad (Ibídem, 2014).

La segunda etapa abarcó el trabajo de campo en el cual se realizaron tomas fotográficas en los meses de diciembre del 2018-enero del 2019. Se visitaron los dos mercados del área de estudio y se hizo observación participante, entre el mes de marzo de dicho año, en la que se observó un predominio entre los visitantes nacionales sobre los extranjeros, quienes asistían para comprar: artesanías, adornos y peinetas de concha de mar y dulces de tamarindo, entre otros.

Las técnicas en que se apoyó el estudio fueron cualitativas dado que, se utilizaron la observación participante y la aplicación de un cuestionario comprendido por ocho preguntas de carácter semiestructurada. Además de técnicas cuantitativas a través de la consulta de bases de datos referentes a las características del patrimonio natural, souvenirs, aprovechamiento de los recursos naturales vegetales y turismo nacional e internacional. En este trabajo de gabinete también se recurrió a la consulta de imágenes de satélite, tomas fotográficas y revisión de cartografía impresa y digital. Además de trabajo en campo desarrollado en los mercados "El Pueblito" y "La Diana" del puerto de Acapulco de Juárez, Guerrero celebrado los meses de diciembre de 2018 a noviembre de 2019 en dicho periodo se levantaron 673 cuestionarios y diversas tomas fotográficas.

El instrumento o cuestionario, comprendió diez preguntas con las posibles respuesta de si o no y cuáles, para determinar el porcentaje de turistas nacionales o extranjeros, por un lado, que asisten al área de estudio; además de edad promedio de los turistas que concurren a los mercados "El Pueblito" y "La Diana", a fin de obtener respuestas acerca de qué tipo de turistas nacionales o extranjeros les agrada adquirir los souvenirs, determinar también el país de origen del turista; número promedio de noches de pernocta; determinar el género y porcentaje; la derrama económica durante su estancia; escolaridad de los visitantes; tiempo invertido en el área de estudio.

La fórmula que se empleó para focalizar la población finita a la que se les aplicó a turistas, hombres y/o mujeres, nacionales y/o extranjeros, mayores de 16 años, compradores de souvenirs en los mercados "El Pueblito y "La Diana" de Acapulco, de acuerdo a lo propuesto por Bomba, F. (2018).

$n=\frac{N * Z^{2} * p * q}{\left(e^{2} *(N-1)\right)+Z^{2} * p * q}$

Donde:

$\mathrm{n}=$ Tamaño de la muestra buscado

$\mathrm{N}=$ Tamaño de la población o universo

$\mathrm{Z}=$ Parámetro estadístico que depende el Nivel de Confianza (NC)

$\mathrm{e}=$ Error de estimación máximo aceptado

$\mathrm{p}=$ Probabilidad de que ocurra el evento estudiado (éxito)

$\mathrm{q}=(1-\mathrm{p})$ Probabilidad de que no ocurra el evento estudiado

Para el caso de estudio:

$\mathrm{N}=1,825$ Universo de estudio ( 5 personas diarias entre los dos mercados por 365 días del año).

$\mathrm{Z}=1.96$ Nivel de Confianza que tiene la muestra (95\%)

$\mathrm{e}=3 \%$ Error estimado

$\mathrm{p}=0.5$ Probabilidad de éxito $(50 \%)$

$\mathrm{q}=0.5$ Probabilidad de fracaso $(50 \%)$ 


$$
\begin{gathered}
n=\frac{1825 * 1.96^{2} * 0.5 * 0.5}{\left(3^{2} *(1825-1)\right)+1.96^{2} * 0.5 * 0.5} n=\frac{1825 * 3.84 * 0.5 * 0.5}{(0.0009 *(1824))+3.84^{2} * 0.5 * 0.5} n=\frac{1752}{2.60} \\
n=673.84 \text { cuestionarios }
\end{gathered}
$$

\subsection{Marco Teórico}

Para este trabajo de investigación, se retomó la Teoría General de Sistemas (TGS), propuesta por Ludwig Von Bertalanffy, que analiza cualquier fenómeno a fin de indagar sus causas, características e interrelaciones con otros, donde las partes son más que el todo. La TGS en el sentido más estricto procura derivar, de una definición general de sistema como complejo de componentes interactuantes, conceptos característicos de totalidades organizadas, tales como interacción, suma, mecanización, centralización, competencia, finalidad y aplicarlos entonces a fenómenos concretos (Bertalanffy, 1968).

La TGS, se aplica a una serie de conceptos, principios y métodos que están relacionados con sistemas de todo tipo, incluye por supuesto los de índole turística. Hablar del turismo desde el punto de vista sistémico, es enfocarse en la aplicación de la TGS en esta área, así como de la realización de un estudio de aproximación y representación de la realidad, es adentrarse en el funcionamiento de cada uno de los elementos que lo integran desde una perspectiva holística. En ese sentido, Niño \& González (2013), invocan la perspectiva geográfica al exponer que reside en indagar la causalidad, localización, correlación y evolución de cualquier hecho o fenómeno que se desarrolla sobre la superficie de la Tierra.

En este orden de ideas, el estudio se compone de tres subsistemas: físico (enclave, sitio, lugar); biótico (flora y fauna) y antrópico (hombre y sus actividades económicas). El subsistema físico lo conforman las zonas de estudio, los mercados "El Pueblito" y "La Diana" de Acapulco de Juárez; el subsistema biótico está conformado por las características ambientales entre las que se pueden mencionar la flora y fauna; por último, el subsistema antrópico comprende los locatarios de los mercados antes citados, turistas, comercialización de artesanías con base en recursos naturales de la región como son el coco, la palma, el vástago, la palapa, el hueso de la palma, el tronco, etc., de tal manera que el método geográfico comprende el empleo de cartas temáticas a fin de georreferenciar las áreas de estudio, asimismo para caracterizar a la población locataria y los souvenirs que ofertan (Niño \& Ramos, 2018, figura 9.2).

Figura 9.2 Teoría General de Sistemas (TGS)

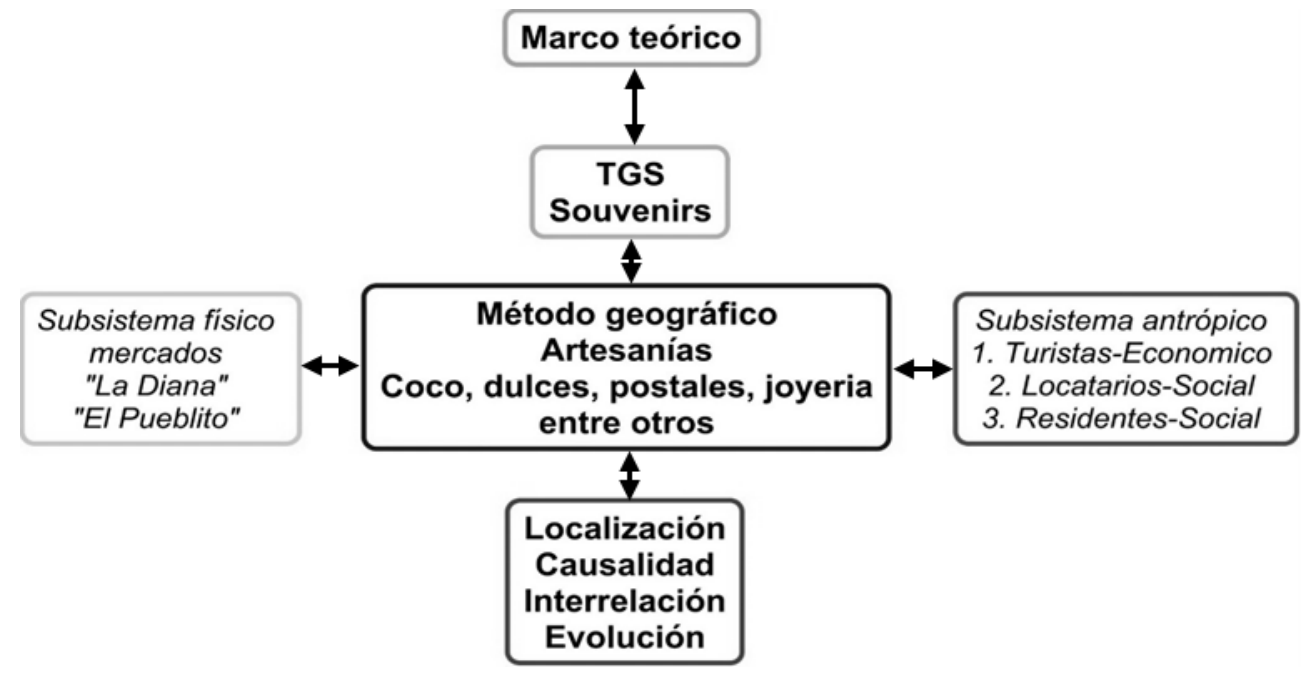

Fuente: Niño, N. (2015) modificado por Rojas, A. (2019)

Se nutre con el abordaje de manera concreta por los conceptos más relevantes de esta investigación donde destacan: artesanías, souvenir, turismo y turismo urbano por lo que, a continuación se detallan: Artesanías, son un sistema integral de trabajo productivo en un marco cultural e histórico, heredado de generación en generación que se circunscribe a un oficio tradicional, a partir de una o varias técnicas de transformación, herramientas simples que se concretizan en la destreza y habilidad del artesano, inserto en inherentes procesos colectivos de identidad proyectados como extensión del pensamiento creador de un grupo (Lorenza \& Pérez, 2011). 
Abduca (2007), afirma que el "etnoarte indígena" adquiere resignificaciones-souvenir turísticoentendiéndose como objetos que sirven para mantener la circulación de los flujos sociales y culturales entre los anfitriones y los visitantes. Si bien para los indígenas sirven a fines utilitarios, a los turistas sirven para decoración, regalos y así se perpetua la metamorfosis de la riqueza capitalista: de medios de producción en acto a productos mercantiles de mercancías a dinero y del dinero en bienes de reproducción, sean de consumo final o de más producción.

Así, los valores de uso de objetos como brazaletes, collares, coronas, cestería, ollas y otros son las mismas, pero este valor de uso esta ahora desdoblado: sirven como mercancías y se ponen a circular. En nuestra concepción el "etnoarte indígena" pasa a tener así un valor desdoblado de uso para los que lo hacen y producen y (resignificaciones) para quienes lo compran (decoración o souvenir). Santana (1997) afirma que donde existen un espacio o una comida propiamente turística, existe un objeto turístico. Este objeto, según el tipo de consumidor turístico y destino, podría ser identificado por sus características obvias: pequeño, barato, no demasiado exótico y poseer la cualidad de connotar simbólicamente el área visitada. Pero se debe mirar más allá del objeto en venta, descubrir cuál ha sido el proceso por el que ahora se encuentra expuesto en un escaparte que invita a su compra a un nuevo público al que, en último término, no le interesa el estilo y la forma simbólica, sino la representación suntuaria y recordatoria, a ejemplo de valor simbólico de Baudrillard.

Souvenir, es la reliquia secularizada o el recuerdo, incluso el complemento de la "vivencia", que se lleva a cabo cuando el hombre hace el inventario de su pasado como pertenencias muertas. La alegoría abandona en el siglo diecinueve el mundo exterior para instalarse en el mundo interior. La reliquia proviene del cadáver, el souvenir de la experiencia difunta, que por un eufemismo se llama vivencia (Walter, 2001).

El souvenir es un objeto que condensa una narrativa específica (un "allí" en un "aquí", una trayectoria personal, un fetiche, un obsequio, un ejemplo de producción en masa, entre otras lecturas posibles) en tanto objetualiza la experiencia, al despojar al paisaje real de sus vicisitudes coyunturales para llevarlo a un mundo interior, familiar domesticado. En tal sentido, no debe pensarse en el souvenir como una mercancía inútil, pues en realidad es el principal comunicador del destino. Circulan de mano en mano que contribuye a generar y consolidar la imagen turística de un destino, comunicándola de una manera más sutil pero no menos efectiva que el asesoramiento de cualquier agente de viajes o página web.

Por otra parte, todo objeto transportable puede devenir en souvenir. El tiempo disfrutado ya no volverá, pero nos queda la servilleta de un bar, el programa de una obra de teatro o el ticket de entrada al museo como depositarios (mediadores) de esa memoria. La industria del souvenir no tiene límites porque los visitantes pueden otorgar ese status a casi cualquier cosa que aprecien en el lugar que disfrutan, siempre y cuando se pueda construir un significado asociativo para con la experiencia vivida.

Es por ello que, el souvenir ocupa un lugar singular entre la objetivación de la experiencia y la subjetivación de la mercancía. No es (solamente) para ser consumido, sino para ser atesorado; no es para darle un uso profano, sino para depositar allí nuestras vivencias pasadas y/o expectativas futuras. De tal manera que “...el souvenir nos dice más del turista que del lugar del cual el souvenir es su representación .... No tenemos, por tanto, turistas que se llevan consigo souvenirs; tenemos souvenirs que encapsulan subjetividades, los sentimientos y las emociones de los turistas" (Estévez, 2008).

Valor simbólico y valor económico que acuñó Thompson (1995), cuando discutió el concepto de cultura y su concepción estructural. Las formas simbólicas que subyacen a su mirada son consideradas como "un amplio espectro de acciones y habla, imágenes y textos que son producidos por sujetos y reconocidos por ellos y otros como constructores significativos" (Thompson, 1999).

El valor simbólico corresponde pues al valor que las formas simbólicas toman, son apreciadas o denunciadas, queridas o despreciadas por grupos o personas. El valor económico se refiere al estatus que las formas simbólicas adquieren cuando se intercambian en el mercado. Cuando las formas simbólicas están sujetas a la valorización económica, se tornan en mercancías o bienes simbólicos que pueden ser comercializados de cualquier manera en el mercado (Ibídem, 1995). 
Turismo, es un fenómeno social, cultural y económico relacionado con el movimiento de las personas a lugares que se encuentran fuera de su lugar de residencia habitual por motivos personales o de negocios/profesionales. Estas personas se denominan visitantes (que pueden ser turistas o excursionistas; residentes o no residentes) y el turismo tiene que ver con sus actividades de las cuales algunas implican un gasto turístico (UNWTO, 2008).

Turismo urbano, consiste en realizar viajes, visitas y estancias en grandes y medianas ciudades y que se pueden efectuar durante un tiempo más o menos prolongado, que puede oscilar entre un fin y una semana (Ver figura 9.3). Las principales actividades turísticas que se pueden desarrollar en el turismo urbano son las siguientes: a) Visita urbanística. Histórico-monumental y museística de la ciudad, así como sus exposiciones permanentes; b) Visita de exposiciones y manifestaciones culturales que se organicen de forma eventual o temporal; c) Actividades gastronómicas y de restauración típicas de la ciudad o de la zona; d) Asistencia a manifestaciones culturales y artísticas que se desarrollan de forma estable o temporal: cine, teatro, opera, festivales de música y danza y e) Compras (shopping) en grandes almacenes o establecimientos especializados (Montaner, Antich \& Arcarons,1998).

Figura 9.3 Turismo urbano

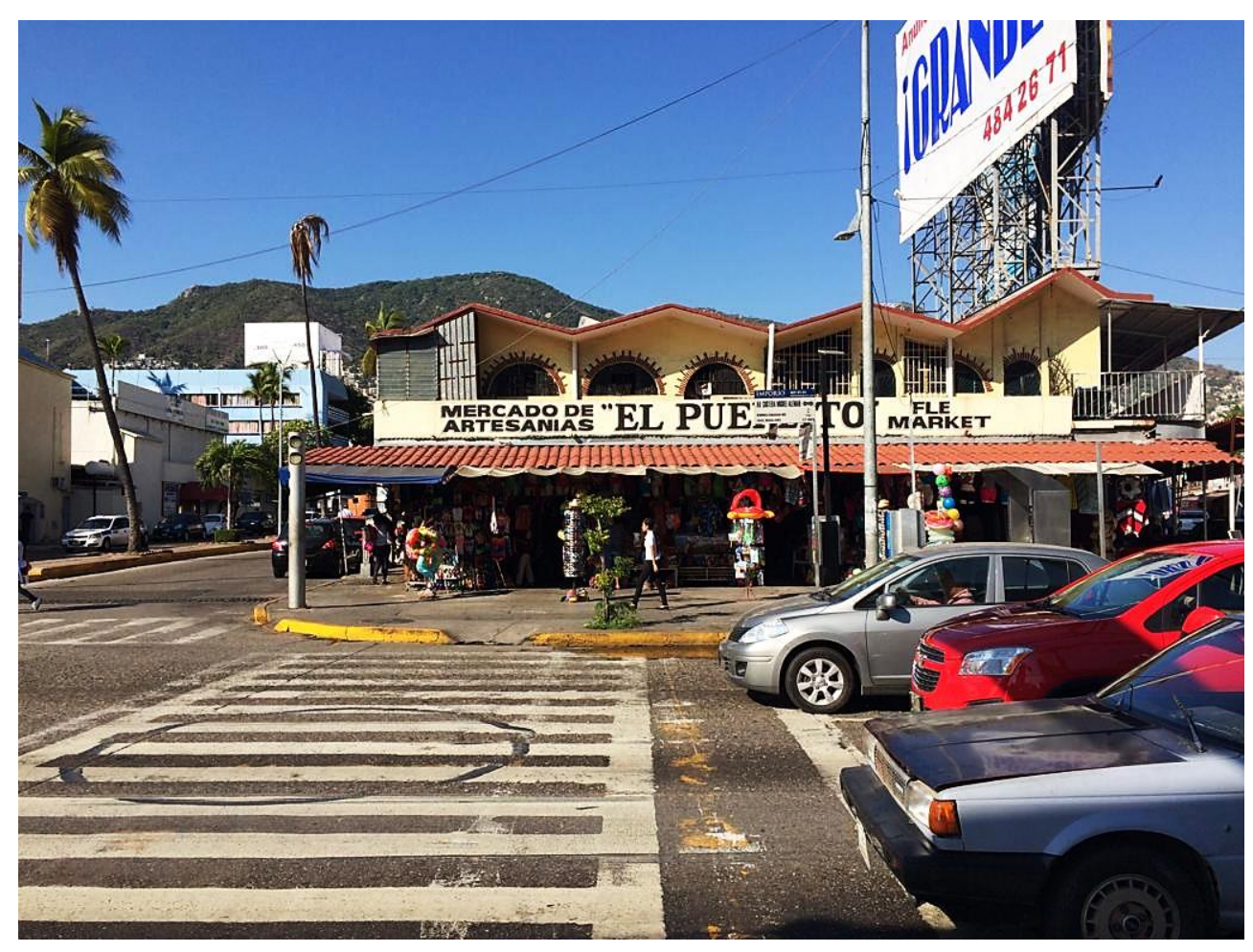

Fuente: Rojas, 2019

\subsection{Resultados}

Se tuvo la oportunidad de aplicar el cuestionario a 673 turistas entre nacionales procedentes del estado de México, Ciudad de México, Hidalgo, Puebla, Estado de Morelos, Michoacán, del interior de Guerrero y extranjeros procedentes de Cuba, Argentina, Canadá y Estados Unidos de América, quienes argumentaron que los souvenirs, son productos que atesoran como recuerdos de la visita a lugares distintos a sus lugares de residencia a fin de recordar su estancia en este caso el destino de sol y playa conocido como Acapulco de Juárez, Guerrero, México. Porque, aquí se ofertan artesanías únicas en el mundo elaboradas con base en el coco como son: aceites, jabones, bolsos, sombreros entre otros. Mismo que desean compartir con familiares y amigos ello queda sintetizado en la Tabla 9.1. 
Tabla 9.1 Las artesanías (souvenir/recuerdo) como primera opción de compra

\begin{tabular}{|l|r|}
\hline \multicolumn{1}{|c|}{ Artesanías } & Número de repeticiones \\
\hline Llaveros & 196 \\
\hline Ropa & 126 \\
\hline Bolsos & 42 \\
\hline Conchitas & 28 \\
\hline Plumas & 28 \\
\hline Carteras & 14 \\
\hline Ranitas & 14 \\
\hline Calaveritas & 14 \\
\hline Collares & 14 \\
\hline Sombreros & 14 \\
\hline Alhajeros & 14 \\
\hline Tazas & 14 \\
\hline Barcos & 14 \\
\hline Dulces & 14 \\
\hline Tamarindos & 14 \\
\hline Hamacas & 14 \\
\hline Jarros de barro & 14 \\
\hline Lámparas & 14 \\
\hline
\end{tabular}

Fuente: Rojas, 2019

De los 673 turistas a quienes se les aplicaron los cuestionarios al menos 638 contestaron que está en su primera opción de compra adquirir un souvenir o recuerdo de su estancia en este puerto de Acapulco, lo que representó el $94.7 \%$ en tanto que el 5.3\% no compran souvenirs o es su segunda opción. De manera esquemática se puede apreciar en la Figura 9.4.

Figura 9.4 Representación de los souvenirs adquiridos por los turistas

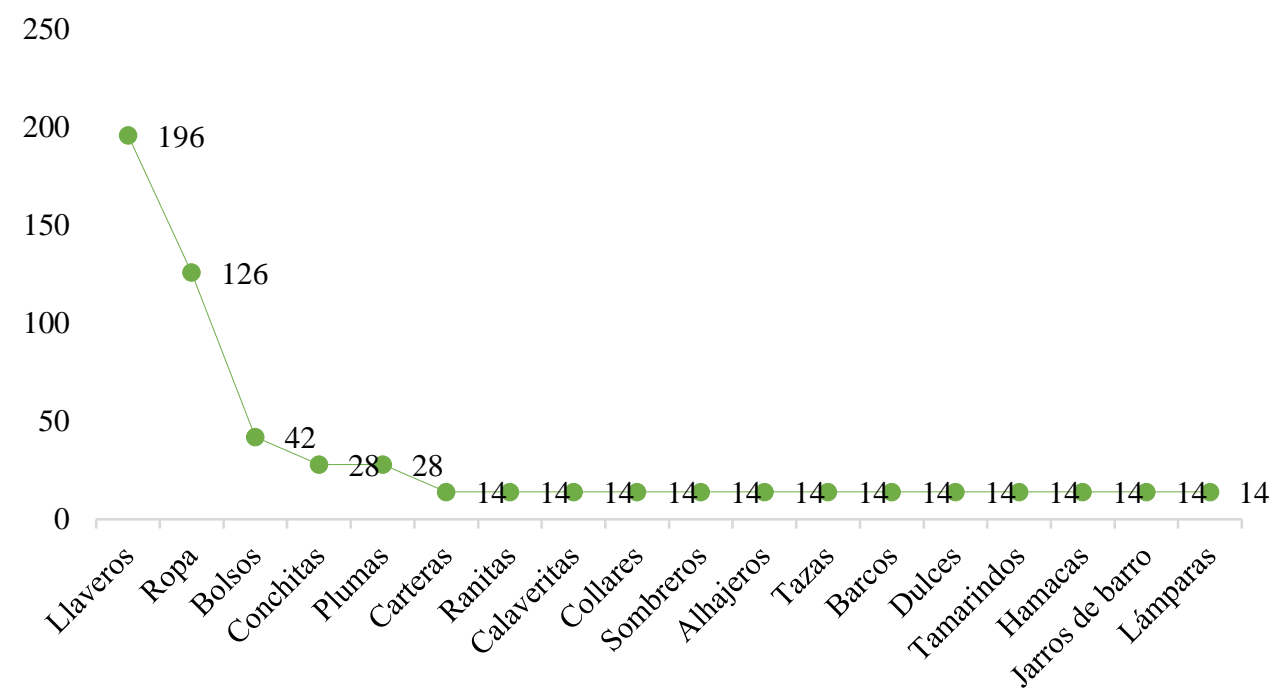

Fuente: Rojas, 2019

Las piezas únicas (ver Figura 9.5), elaboradas en las localidades como: Plan de los Amates municipio de Acapulco o en el interior de la ciudad de Acapulco como es el caso de la Colonia: Zapata y Ciudad Renacimiento. A fin de ofertarlos en los mercados de artesanías "El Pueblito" y "La Diana" (Figura 9.6) sobre la avenida más transitada de Acapulco que es la Avenida Costera Miguel Alemán Velasco. Cuya ubicación está determinada por la cercanía a la playa, el casino E-Motion, Los hoteles El Club del Sol, HS Hotsson Smart Acapulco, el centro Comercial Av. Costera 125, la Plaza bahía, Gran Plaza Acapulco y diversos locales de conveniencia, entre otros. 
Figura 9.5 Número de repeticiones de los souvenirs locales

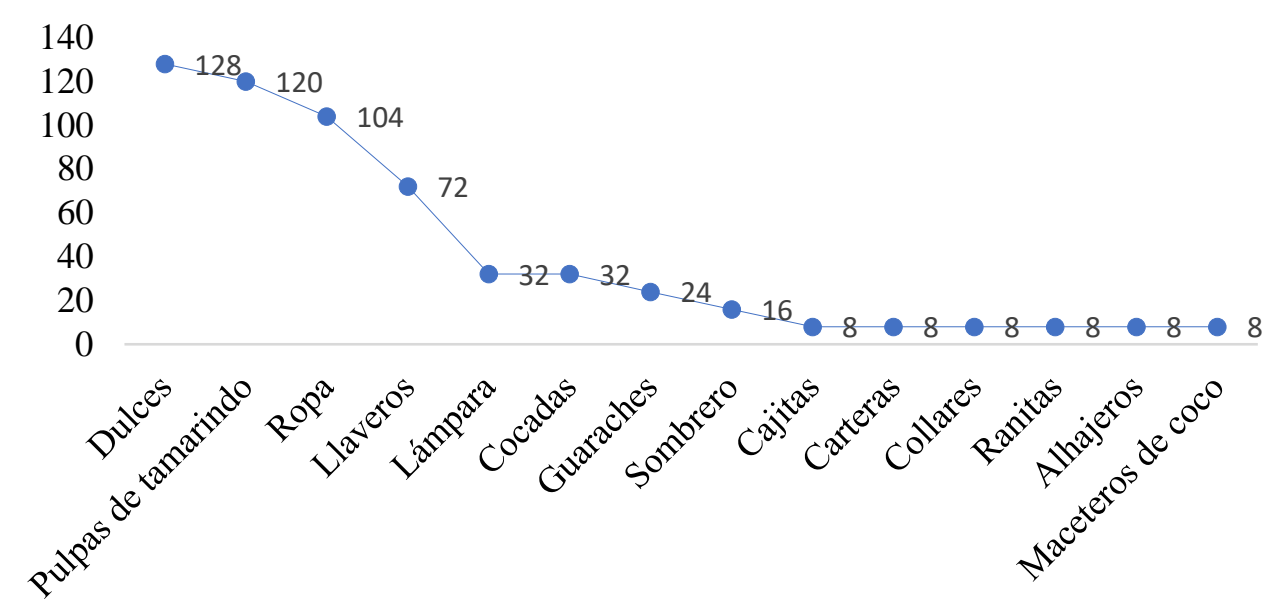

Fuente: Rojas, 2019

Figura 9.6 "La Diana"

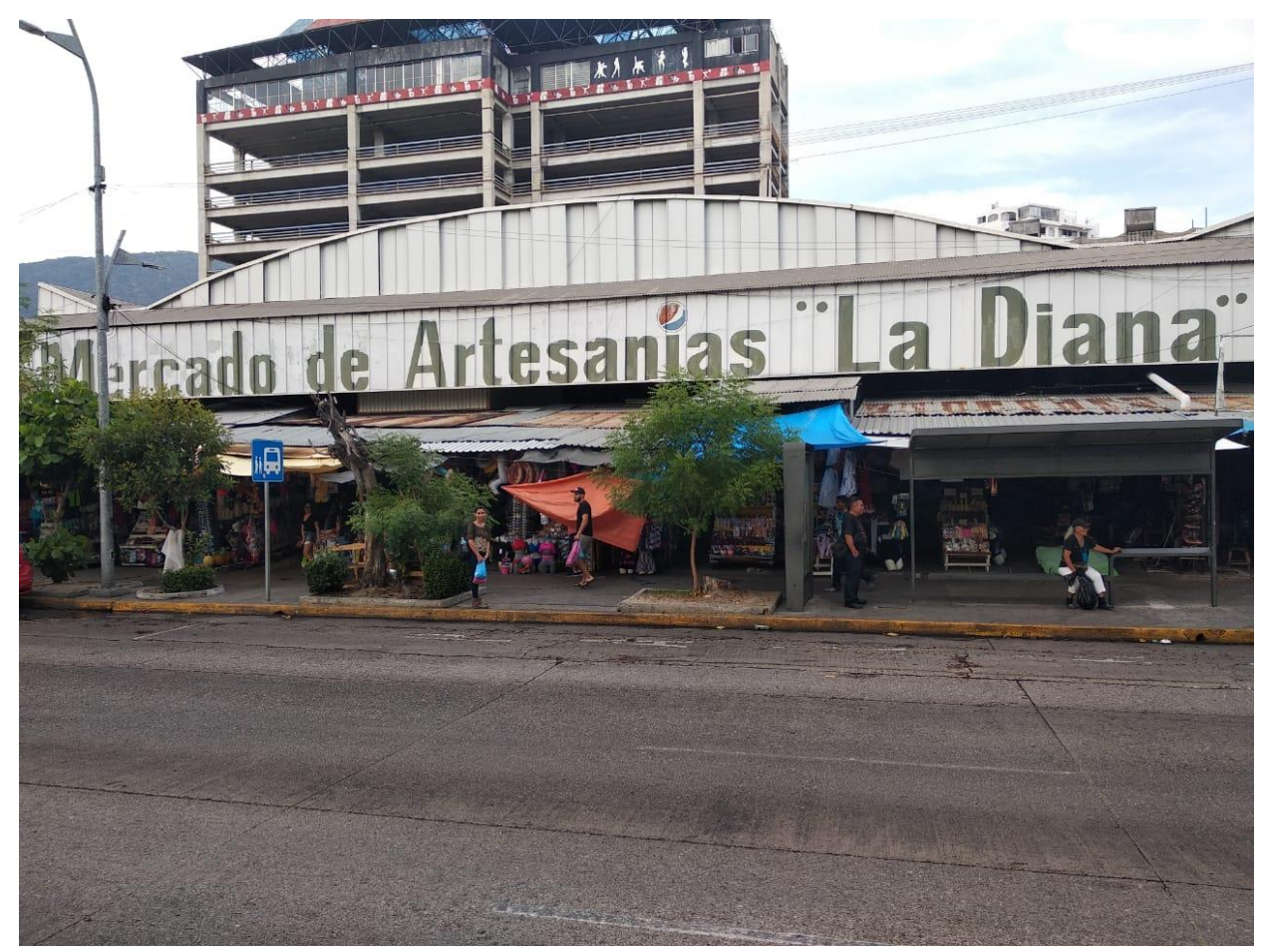

Fuente: Rojas, 2019.

Los turistas aceptaron que destinan un promedio de $\$ 135.00$ (Ciento treinta y cinco pesos Moneda Nacional), aunque los extremos quedaron representados por la cantidad de $\$ 380.00$ (trescientos ochenta pesos Moneda Nacional) lo que significó 15 repeticiones (2.2\%) para la adquisición de ropa en tanto que, la menor cantidad destinada a la compra de souvenirs fueron maceteros de coco y decoraciones con base en estrellas de mar con sólo cuatro repeticiones. Por lo que, los nexos entre souvenirs y turismo son cada vez más sutiles dado que la falta el poder adquisitivo de los turistas es cada vez de menor envergadura (Tabla 9.2). 
Tabla 9.2 Cantidades destinadas por los turistas a la compra de artesanías

\begin{tabular}{|r|r|r|}
\hline Moneda & Número de repeticiones & \% de repeticiones \\
\hline$\$ 380$ & 15 & 2.2 \\
\hline$\$ 355$ & 15 & 2.2 \\
\hline$\$ 285$ & 15 & 2.2 \\
\hline$\$ 200$ & 15 & 2.2 \\
\hline$\$ 190$ & 15 & 2.2 \\
\hline$\$ 152$ & 15 & 2.2 \\
\hline$\$ 140$ & 15 & 2.2 \\
\hline$\$ 133$ & 45 & 6.6 \\
\hline$\$ 95$ & 135 & 20.0 \\
\hline$\$ 60$ & 15 & 2.2 \\
\hline$\$ 50$ & 60 & 8.9 \\
\hline$\$ 30$ & 300 & 44.5 \\
\hline
\end{tabular}

Fuente: Rojas, 2019

Acorde al número de turistas que manifestaron haber comprado dichos souvenirs en los mercados objeto de estudio. Las artesanías que más se venden son la ropa tradicional guerrerense, llaveros con efigies sobresalientes de Acapulco, botellas de arena con la marca Acapulco, pulseras de diversos colores en tanto que, los productos con base en el coco ocupan el quinto lugar de preferencia y como séptimo lugar los dulces de coco (Figura 9.7).

Figura 9.7 Orden descendente de las referencias hechas por los turistas

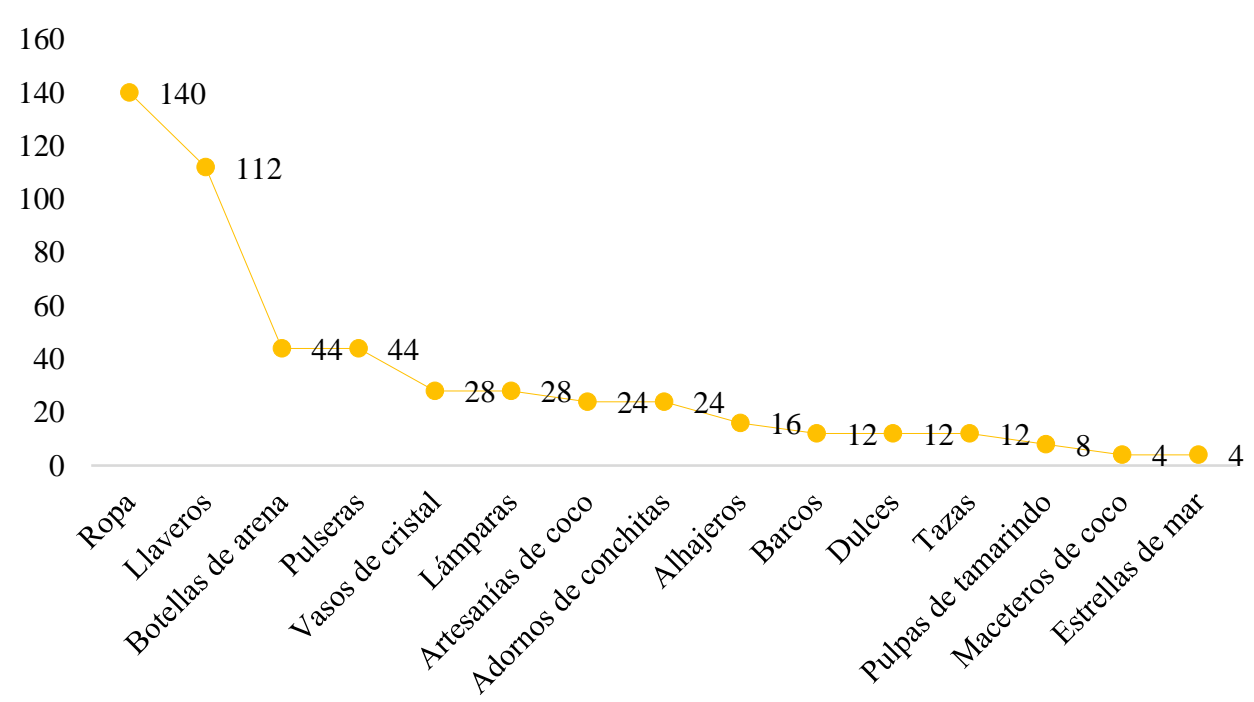

Fuente: Rojas, 2019

\subsection{Acciones a tomar en cuenta para mejorar}

1) Que los artesanos y artesanas guerrerenses sean capacitados para la transición de la venta directa hacia la venta Online.

2) Que los artesanos y artesanas mayores consolidan la innovación de sus piezas únicas ricas en identidad, cultura y tradiciones hacia las nuevas generaciones.

3) La continuación de la política pública estatal para la promoción y consolidación del Programa "Así es Guerrero" a fin de que se acuñe como marca y sea reconocido en diferentes latitudes. 


\subsection{Conclusiones}

Acorde con los resultados obtenidos en la presente investigación, se concluye que los turistas nacionales y extranjeros que visitan el Puerto de Acapulco, Guerrero, México tienen en su imaginario adquirir uno o más souvenirs como recuerdo para compartir su experiencia con la familia y amigos; otro nexo entre los souvenirs y turismo es que tienen apego por la adquisición de productos artesanales elaborados con base en recursos vegetales como por ejemplo, el coco seco con figuras diversas, sombreros de palma, bolsos, aceite de coco, jabones de coco, cremas y dulces de tamarindo, entre otros. Sin embargo, los recursos económicos que ingresan a los artesanos son ínfimos debido a la recesión económica por la que atraviesa la economía mexicana. Además de que, los locatarios mencionan que es importante que los mercados "El Pueblito" y "La Diana" sean remozados y de ser posible apoyados económicamente por autoridades municipales para mejorar la iluminación de los andadores interiores de ambos mercados, pintura de los locales así como seguridad para todos y todas.

En cuanto a la metodología empleada resultó idónea para explicar de manera holística los nexos aún existentes entre el turismo-souvenirs. Los turistas nacionales son los que hacen las mejores inversiones en la compra de los souvenirs pese a la recesión económica que se vive actualmente en la economía mexicana, lo cual tiene relación con la pérdida del interés de las nuevas generaciones para dedicarse a la sostenibilidad de la actividad artesanal vinculado con el cuidado del medio ambiente natural local cuya identidad se encuentra ligada a la existencia de los elementos de la naturaleza. De ahí la importancia de la difusión de la actividad artesanal en todas sus manifestaciones en cada uno de los sitios del orbe entero donde la innovación jugará un rol importante en el futuro próximo.

El objetivo central del estudio se logró dado que los 673 turistas entre nacionales y extranjeros contestaron que cuando arriban a Acapulco piensan adquirir algún o algunos souvenirs para recordar su estancia en este puerto. Entre los souvenirs más solicitados estuvieron: ropa, llaveros, botellas de arena, pulseras, vasos de cristal, lámparas, artesanías de coco, adornos de conchitas, alhajeros, barcos, dulces, tazas, pulpas de tamarindo, maceteros de coco y estrellas de mar (ver Figura 9.8).

Figura 9.8 Variedad de Souvenirs

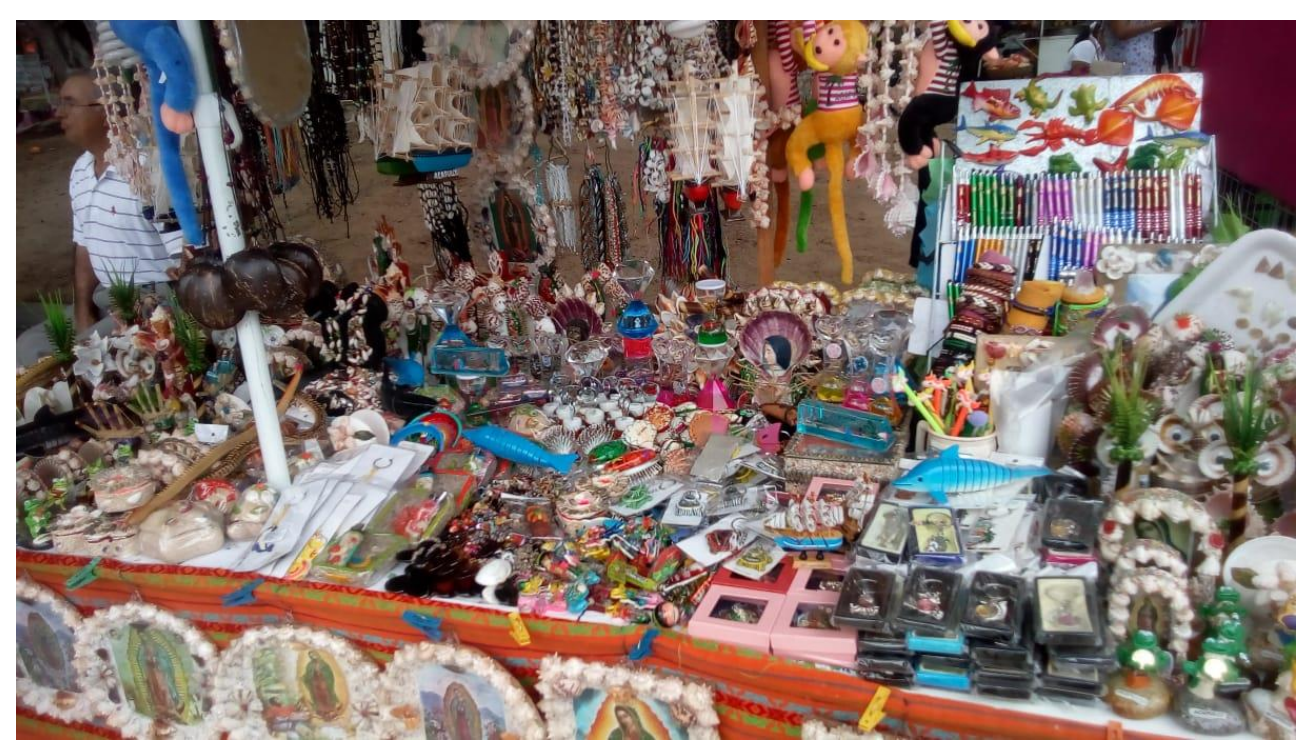

Fuente: Rojas, 2019 


\section{Anexo Número 1. Cuestionario}

\section{Universidad Autónoma de Guerrero \\ Facultad de Turismo \\ Maestría en Ciencias: Gestión Sustentable del Turismo}

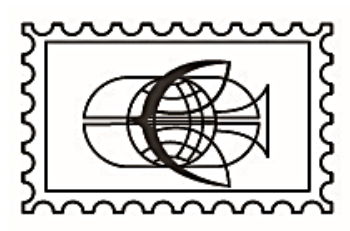

Instrucción: Cruza el círculo que, según su experiencia mejor responda cada pregunta.

Nota: La información es confidencial y solo con fines estadísticos.

1. ¿Es mayor de 16 años de edad?

Si $\bigcirc$ No $\bigcirc$

2. ¿Nos visita del interior de México?

Si $\bigcirc$ No $\bigcirc$ Otro país

3. ¿En su primera opción de compra como souvenir/recuerdo están las artesanías?

Si $\bigcirc$ No $\bigcirc$ ¿Cuál?

4. ¿Comprará usted un producto local como souvenir/recuerdo?

Si $\bigcirc$ No $\bigcirc$ ¿Cuál?

5. ¿Compró alguna pieza decorativa como souvenir/recuerdo?

Si $\bigcirc$ No $\bigcirc$ ¿Cuál?

6. ¿Destinará al menos un dólar americano a la adquisición de un souvenir local?

Si $\bigcirc$ No $\bigcirc$ ¿Cuánto?

7. ¿Cree que existen fuertes lazos entre souvenirs y turismo?

Si $\bigcirc$ No $\bigcirc$ ¿Cuánto?

8. ¿Adquirió artesanías con base en coco?

Si $\bigcirc$ No $\bigcirc$ ¿Cuál?

9. ¿Prefirió dulces de tamarindo?

Si $\bigcirc$ No $\bigcirc$

10. ¿Compró el souvenir en "El Pueblito y/o "La Diana?

Si $\bigcirc$ No $\bigcirc$ ¿Cuál? 


\subsection{Referencias}

Abduca, R. (2007). La reciprocidad y el don no son la misma cosa. Cuadernos de Antropología Social, 1(26), 107-124. Recuperado de http://www.redalyc.org/articulo.oa?id=180914245006

Bertalanffy, L. (1968). Teoría General de los Sistemas. México: Fondo de Cultura Económica.

Bomba, F. (2018). Tamaño de la muestra paso a paso. Recuperado de https://www.youtube.com/watch?v=oc8i9g144Y0

Burguete, L. (2007). Desarrollo sustentable y participación social. CDMX: INECC-SEMARNAT. Recuperado de http://www2.inecc.gob.mx/publicaciones2/libros/398/burguete.html

CONACOCO (2017). Todo sobre el cultivo del cocotero. Consejo Nacional del Cocotero. Recuperado de http://www.conacoco.com.mx/coco/nueva/cultivo/cultivo_coco.htm

Estévez, F. (2008). Narrativas de seducción, apropiación y muerte o el souvenir en la época de la reproductibilidad turística. Acto: revista de pensamiento artístico contemporáneo, 1(4), 34-49. Recuperado de https://reacto.webs.ull.es/pdfs/n4/estévez.pdf

Lesur, L. (2006). Manual del guía de turistas. Una guía paso a paso. México: Trillas.

Lorenza, G. y Pérez, C. (2011). Artesanía y diseño. Diálogos y prácticas pedagógicas. 1(3), 109-120. Recuperado de https://dialnet.unirioja.es/servlet/articulo?codigo=5654052

Montaner, J., Antich, J. \& Arcarons, R. (1998). Diccionario de Turismo. Madrid: editorial.

Niño, N. (2015). Propuesta de Modelo Sociogeográfico Niño (MSNiño) para Áreas Naturales Protegidas de México (1992-2014). Revista de Investigaciones Sociales, 1(2),128-137. Recuperado de www.ecorfan.org/republicofnicaragua

Niño, N. y Bergeret, R. (2012). Atractivos del turismo cultural en Acapulco. Revista Altamirano. 1(42), 65-80. Recuperado de www.iepen.org

Niño, N. y Bergeret, R. (2014). Vivienda e indicadores de insustentabilidad en los fraccionamientos de Cayacos y Tunzingo de Acapulco. En Alcaraz, O. y Salgado, A. (Coords.). Una visión diferente de la vivienda en Guerrero. México: JP-SEDATU-ITA-UAGRO. 1(1), 97-112.

Niño, N. y González, D. (2013). Propuesta metodológica para la planeación sostenible de Áreas Naturales Protegidas en Latinoamérica. Cuadernos /Con-Texto 3. 1(3), 65-76.

Niño, N. y Ramos, M. (2018). Planificación financiera fractal de la zonificación para la isla La Roqueta. Investigación, Cultura, Ciencia y Tecnología. 19(10), 8-14.

Rojas, A. (2019). Fotografías de Turismo y Souvenirs en los mercados "El Pueblito" y "La Diana" de Acapulco de Juárez, Guerrero. Inédito.

Ruiz, J. \& Niño, N. (2014). El turismo en las bahías de Papanoa. En Niño, N., Bergeret, R. y Díaz, A. (Coords.). Gestión Sustentable del Turismo. PRAXIS-UAGRO. pp. 17-25.

Santana, A. (1997). Antropología y turismo: ¿nuevas bordas, viejas culturas?. Barcelona: Ariel. Antropología.

Thompson, J. (1995). Ideología e Cultura Moderna: teoría social crítica na era dos meios de comunicação de massa. Petropólis, RJ: Vozes.

Thompson, J. (1999). A mídia e modernidade: uma teoria social da mídia. Petrópolis, RJ: Vozes. 
UNWTO. (2008). Glossary of tourism terms. World Tourism Organization. Recuperado de https://media.unwto.org/es/content/entender-el-turismo-glosario-basico

Walter, B. (2001) Siete ensayos. Buenos Aires: Fondo de Cultura Económica.

Yasmin, C. (2009). Proyecto de desarrollo productivo cadena de valor frutícola; análisis del mercado para coco. Recuperado de http://es.scribd.com/doc/99334390/2009-FOMILENIO-Analisis-deMercado-para-Coco 